\title{
Microstructure of Coal Gangue and Precipitation of Heavy Metal Elements
}

\author{
Yanli Huang, Junmeng Li, Tianqi Song, Qiang Sun, Guoqiang Kong, and Fengwan Wang \\ School of Mines, State Key Laboratory of Coal Resources and Safe Mining, China University of Mining \& Technology, \\ Xuzhou 221116, China \\ Correspondence should be addressed to Junmeng Li; lijunmeng1201@163.com
}

Received 6 July 2017; Accepted 17 September 2017; Published 23 November 2017

Academic Editor: Yao-Jen Tu

Copyright (C) 2017 Yanli Huang et al. This is an open access article distributed under the Creative Commons Attribution License, which permits unrestricted use, distribution, and reproduction in any medium, provided the original work is properly cited.

\begin{abstract}
The microstructure and mineral composition of the gangue play a decisive role in the precipitation of heavy metal elements. In this study, the microstructure, mineral composition, and precipitation of heavy metal elements of coal gangue with different weathering degrees were analyzed through electron microscopy, X-ray diffraction, and static immersion leaching experiments. The following results were derived. (1) After the weathering of the coal gangue, its compactness and integrity changed significantly. The coal gangue structure transformed from relatively dense to relatively loose, and the development of large pores and fractures changed from basically no development to significant development. (2) After weathering, the contents of kaolinite and illite significantly increased, while that of feldspar significantly decreased. Coal gangue contains a small amount of $\mathrm{Mn}, \mathrm{Cu}, \mathrm{Zn}, \mathrm{Ti}, \mathrm{Ba}, \mathrm{Cl}, \mathrm{and}$ other elements. After weathering, the contents of each element were reduced. (3) Under the same conditions, a higher number of heavy metal elements precipitated from the weathered coal gangue than from the fresh coal gangue. The results of this research have significant importance in revealing the precipitation mechanism of heavy metals from coal gangue and in perfecting the theory of underground water environmental protection during solid backfilling mining.
\end{abstract}

\section{Introduction}

In addition to containing a large number of major elements including $\mathrm{C}, \mathrm{Si}, \mathrm{Al}, \mathrm{Fe}, \mathrm{Ca}$, and $\mathrm{Mg}$, coal gangue also contains a variety of trace heavy metal elements. Under long-term weathering and rain leaching, these heavy metal elements cause pollution in the groundwater, surface water, and soil. In the fully mechanized solid backfilling coal mining, the bottom-well environment is relatively closed, dark, and humid, while the ground stress and terrestrial heat are high. In addition, the overlying cap rock fracture development and coal mining process will result in mine water emission; thus, the coal gangue fillings in the goaf are consequently always immersed in a water environment [1-3]. After longterm mine-water leaching and soaking, the heavy metal elements and inorganic salts in this part of the coal gangue will be released after dissolving in water. Under certain conditions, these elements will migrate in the goaf and floor areas with the flow of mine water and may penetrate into the underlying aquifers, causing a potentially significant impact on the groundwater environment. Some of the coal gangue used in solid backfilling coal mining is fresh, that is, just out of the well or obtained directly from sorting at the downhole; however, some is weathered gangue obtained from the ground gangue hill after long-time weathering $[4,5]$. The microstructures and mineral compositions of fresh and weathered coal gangue are different and play a decisive role in the precipitation of heavy metal elements. Therefore, it is important to study these two features at different weathering degrees to reveal the precipitation mechanism of heavy metal elements in coal gangue and to improve the theory of groundwater environmental protection for solid backfilling in coal mining.

In recent years, domestic and foreign scholars have conducted a series of useful fundamental research on the microstructure of coal gangue, its mineral components, and precipitation mechanism of heavy metal elements in coal gangue. Wu [6] analyzed the microstructure of different solid backfilling materials through scanning electron microscopy (SEM) and then studied the internal mechanism 


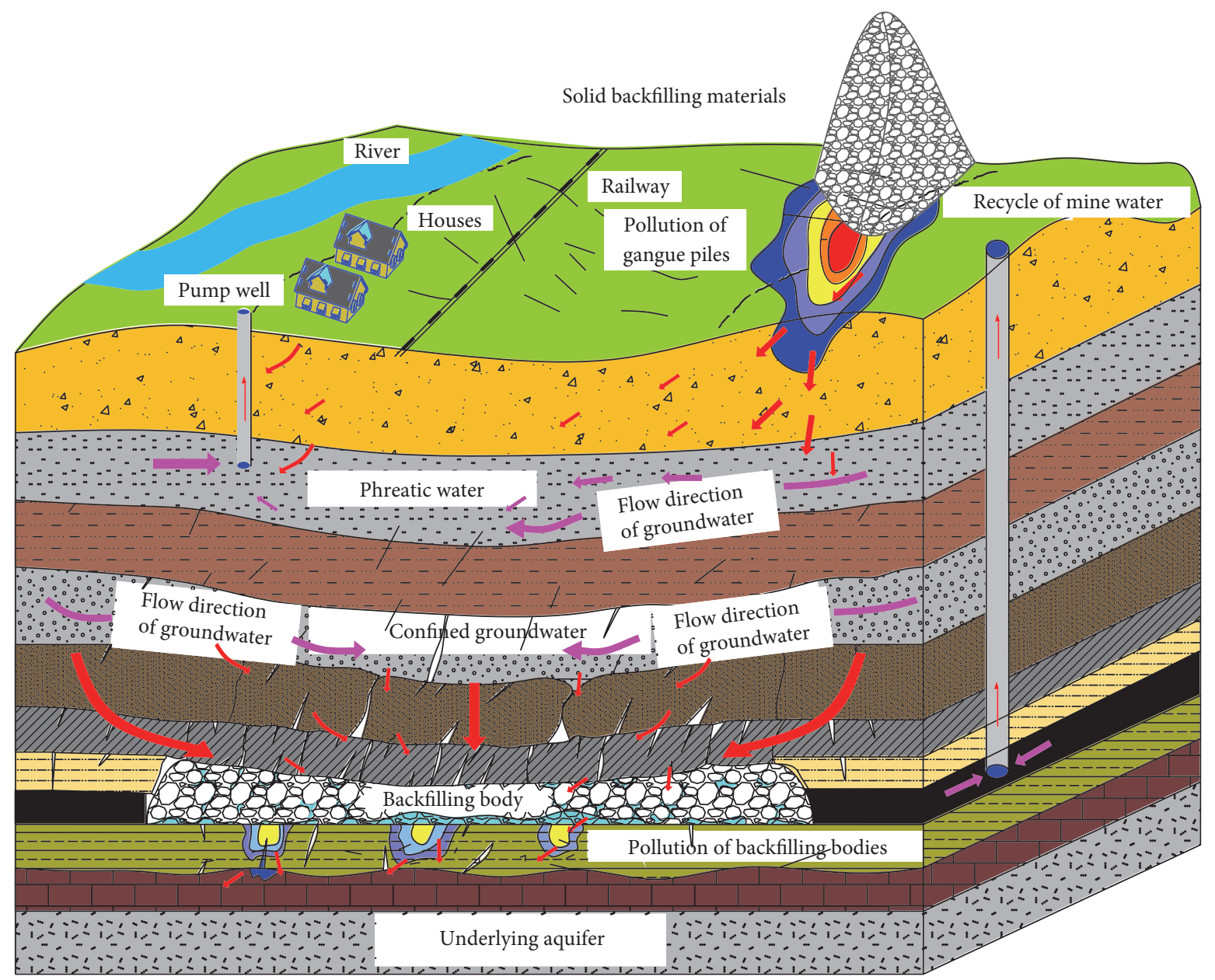

FIGURE 1: Schematic of groundwater pollution from coal gangue backfilling in goaf.

of compaction deformation. $\mathrm{Li}$ and $\mathrm{Wu}$ [7] performed X-ray diffraction (XRD) analysis on clay minerals and found that the chemical weathering in this area was obvious, and significant development of clay minerals was observed in the weathered rock. Shang et al. [8] analyzed the mineral composition of weathered granite through XRD. Li [9] performed a 40-day static immersion leaching test on coal gangue with different weathering degrees in the Huangling number 1 mine in northern Shaanxi. He measured the concentration and $\mathrm{pH}$ of seven types of trace elements including $\mathrm{Cu}, \mathrm{Zn}, \mathrm{Cr}$, and $\mathrm{Pb}$ in the leaching solution. Li et al. [10] performed dynamic leaching tests on four types of coal gangue with different particle sizes in the Pingdingshan number 12 mine, Henan Province, and monitored the concentration of heavy metal elements $\mathrm{Zn}, \mathrm{Mn}$, and $\mathrm{Cd}$ in the leaching solution. Their results showed that the content of heavy metal elements in the leaching solution is inversely proportional to the coal gangue particle size. However, no research has been conducted on the precipitation of heavy metal ions of coal gangue by considering different weathering degrees under leaching conditions. In this paper, electron microscopy, XRD, and static immersion leaching experiments were performed to reveal the precipitation mechanism of heavy metal elements of coal gangue with different weathering degrees under leaching conditions from two aspects: microstructure and mineral composition of the coal gangue.

\section{Influence of Coal Gangue Backfilling on the Groundwater Environment}

The coal goaf area is a long-term relatively closed, dark, and humid environment. Influenced by the mining depth, geothermal and mine water, and other effects, this area is a relatively closed environment of high stress, where temperature is generally higher than the normal temperature (i.e., the temperature of a part of the goaf area affected by geothermal heat can reach $303.15 \mathrm{~K} 313.15 \mathrm{~K}$ or above). In addition, water can seep out because of the development of fractures in the overlaying cap rock; during the development of coal seam, the coal gangue filled into the goaf will always be immersed in a water environment. After long-term mine water leaching and soaking, the heavy metal elements and inorganic salts in this part of the coal gangue will be released after dissolving in water. Under certain conditions, these elements will migrate in the goaf and floor areas with the flow of mine water and may penetrate into the underlying aquifers, 


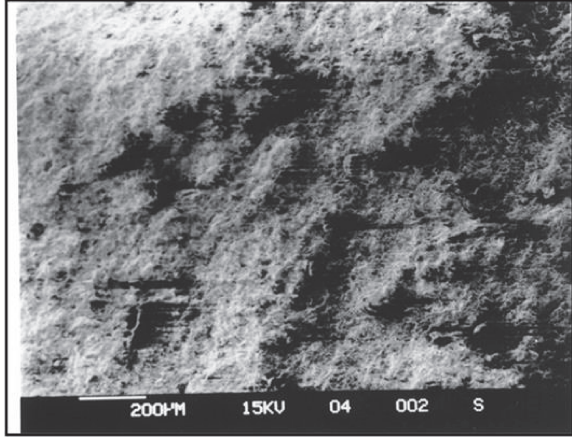

Dense structure

(a) 80 times-general picture

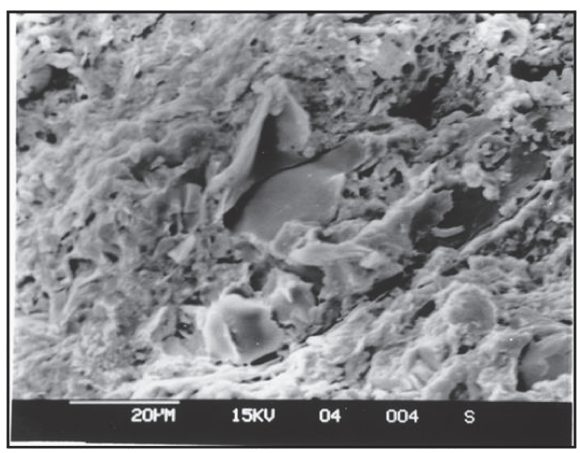

No development of fine pores and fractures in fine-grained clay and no visible layer distribution

(c) 600 times-enlarged

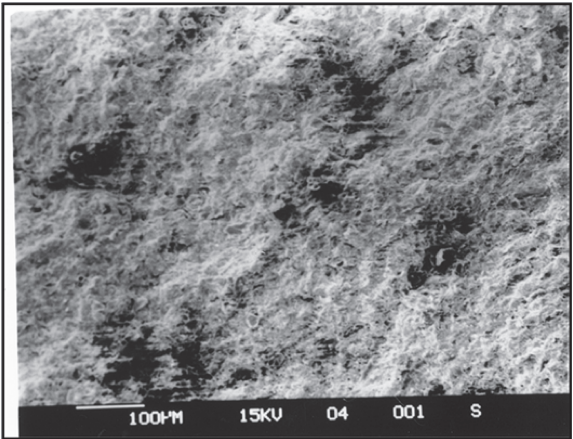

No development of large pores or fractures

(b) 160 times-enlarged

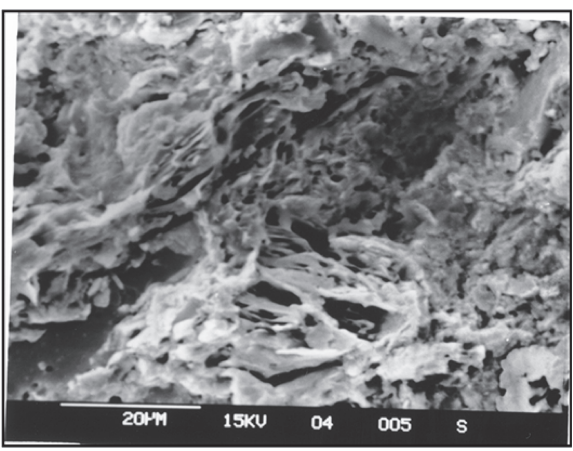

"Cement" structure between coarse

mineral and clay and no development of pores

(d) 800 times-enlarged

FIgURE 2: SEM images of the fresh coal gangue at different resolutions.

causing a potentially significant impact on the groundwater environment, as shown in Figure 1.

\section{Test Equipment and Material Selection}

3.1. Main Test Equipment. The test was completed by scanning electron microscopy (SEM), X-ray diffractometer, and inductively coupled plasma (ICP) atomic emission spectroscopy. The current study analyzed the compactness of coal gangue with different weathering degrees by using an FEI Quanta $^{\mathrm{TM}} 250$ scanning electron microscope. This study qualitatively and quantitatively analyzed the mineral and chemical compositions of coal gangue with different weathering degrees through a D/Max-3B X-ray diffractometer $[11,12]$ (produced by Japan Rigaku Corporation). The incident light was $\mathrm{Cu}$ target $\mathrm{K} \alpha$ radiation $(\lambda=1.5406 \AA)$, the $\mathrm{X}$-ray tube operation voltage was $35 \mathrm{kV}$, the current was $30 \mathrm{~mA}$, and the slit width was $1^{\circ}$. Inductively coupled plasma (ICP) atomic emission spectroscopy was used to determine the major, trace, and ultratrace element contents in various substances (which can be dissolved in hydrochloric acid, nitric acid, hydrofluoric acid, etc.). This instrument can be used for analyzing solid and liquid sample elements, such as rock soil, alloy materials, chemical raw materials, inorganic and organic products, water samples, foodstuffs, plants, animals, and oils.
3.2. Selection of Test Materials. In this study, the gangue to be filled in the Pingdingshan 12 coal mine was selected as the main research object. The gangue mined out from the well was used as the fresh coal gangue and that on the surface of the gangue hill was used as the weathered coal gangue. The "snake sampling method" was used to determine 20 sampling points, after mixing the samples of each sample point, sampling through the "cone quartering" method, and then repeating these steps once again.

\section{Analysis of Gangue Compactness Based on SEM}

The sample compactness was analyzed through SEM, and the SEM images of fresh and weathered coal gangue were obtained under different resolution conditions, as shown in Figures 2 and 3.

Figures 2 and 3 show that the structure of fresh coal gangue is relatively dense, the surface is uneven, and there are no development of large pores or fractures. In contrast, the structure of the gangue becomes relatively loose after weathering, it was uneven, and there was obvious development of large pores and fractures. After the weathering, the compactness and integrity of the gangue were observed to change significantly; this would have an important influence 


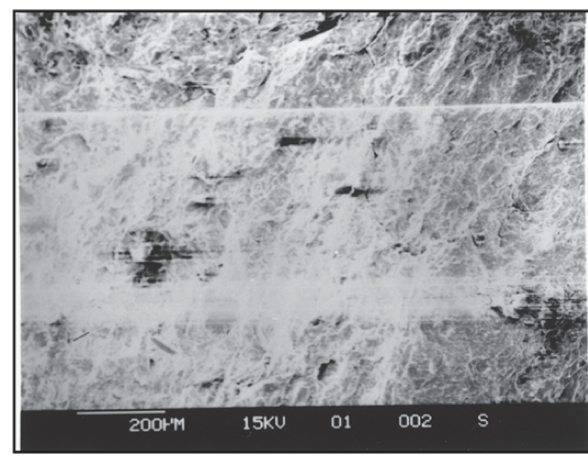

Relative loose structure

(a) 80 times-general picture

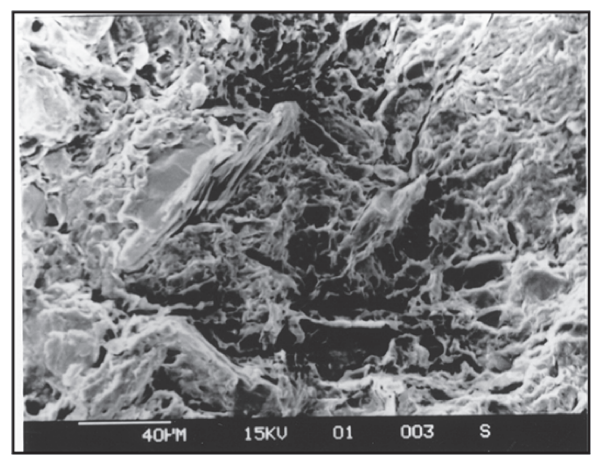

Obvious development of

fine pores and fractures in fine-grained clay

(c) 250 times-enlarged

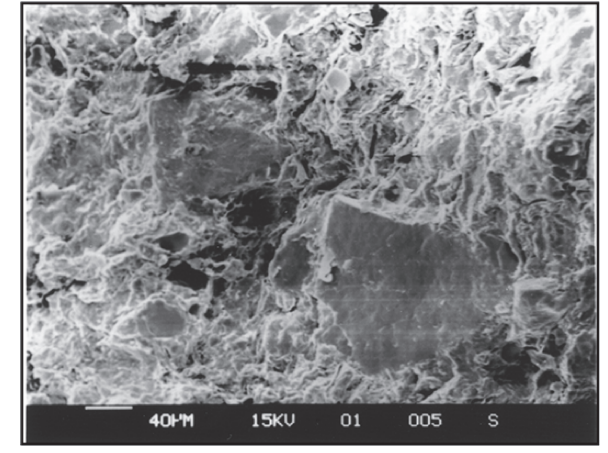

Obvious development of large pores and fractures

(b) 160 times-enlarged

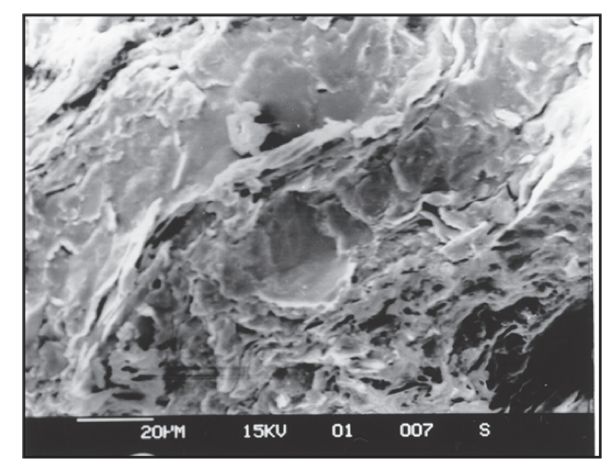

Concentrated partial crystallization, obvious plate-like cementing structure, completed crystalline part

(d) 360 times-enlarged

FIGURE 3: SEM images of the weathered coal gangue at different resolutions.

on the precipitation of heavy metal elements under the leaching condition.

\section{XRD Analysis of Heavy Metal Elements in the Gangue}

5.1. Mineral Composition Characterization. The equipment used in this test is a D/Max-3B type X-ray diffractometer manufactured by Japan Rigaku Corporation. The test conditions were as follows: $\mathrm{Cu}$ target $\mathrm{K} \alpha$ radiation and graphite-bending crystal monochromator. The slit system comprised a $1^{\circ}$ divergence slit (DS), a $1^{\circ}$ receiving slit (RS), a $0.15 \mathrm{~mm}$ antiscattering slit (SS), and a $0.6^{\circ}$ monochromator slit (RSM). Here, the X-ray tube voltage was $35 \mathrm{kV}$ and the X-ray tube current was $30 \mathrm{~mA}$. In the qualitative analysis process, the scanning mode was continuous with a scanning speed of $8 \% \mathrm{~min}$ and a sampling interval of $0.02^{\circ}$. In the quantitative analysis process, the step scanning method was used with a scanning speed of $0.25^{\circ} / \mathrm{min}$ and sampling interval of $0.01^{\circ}$.

The qualitative analysis was conducted using a standard material powder diffraction file (PDF) provided by the International Center for Diffraction Data (JCPDS-ICDD) and was analyzed according to standard analytical methods. The analytical standards used in the quantitative analysis were in accordance with the $K$-value method in the Chinese standard (GB5225-86). The XRD patterns of the fresh and weathered coal gangue are shown in Figures 4 and 5, respectively, and the mineral composition of each sample is shown in Table 1.

The experimental results showed that the mineral compositions of fresh and weathered coal gangue were not significantly different, and the major components are quartz and kaolinite, between which the proportion of kaolinite was the largest, that is, $33 \%$ and $42 \%$, respectively. The components also include illite, illite-montmorillonite mixed layer, and a small amount of chlorite, siderite, pyrite, and other minerals. The amorphous components may be coal or other substances based on the analysis. After weathering, the kaolinite and illite content in gangue increased significantly from 33\% and 5\% to $42 \%$ and $15 \%$, respectively. In other words, the contents increased by $27.3 \%$ and $200 \%$, respectively. The content of feldspar significantly decreased from the original $20 \%$ to $5 \%$; the decline rate is $75 \%$. The minerals generated through coal gangue weathering were observed to be mainly kaolinite and illite, which are obtained from feldspar decomposition.

5.2. Chemical Compositions. Table 2 shows the analysis results of the chemical composition of fresh and weathered coal gangue, respectively.

Table 2 shows that in the material composition of coal gangue, $\mathrm{SiO}_{2}$ is the main component with high content, accounting for $59.9 \%$ and $53.7 \%$ of the fresh and weathered coal gangue, respectively. The secondary element is $\mathrm{Al}_{2} \mathrm{O}_{3}$, 


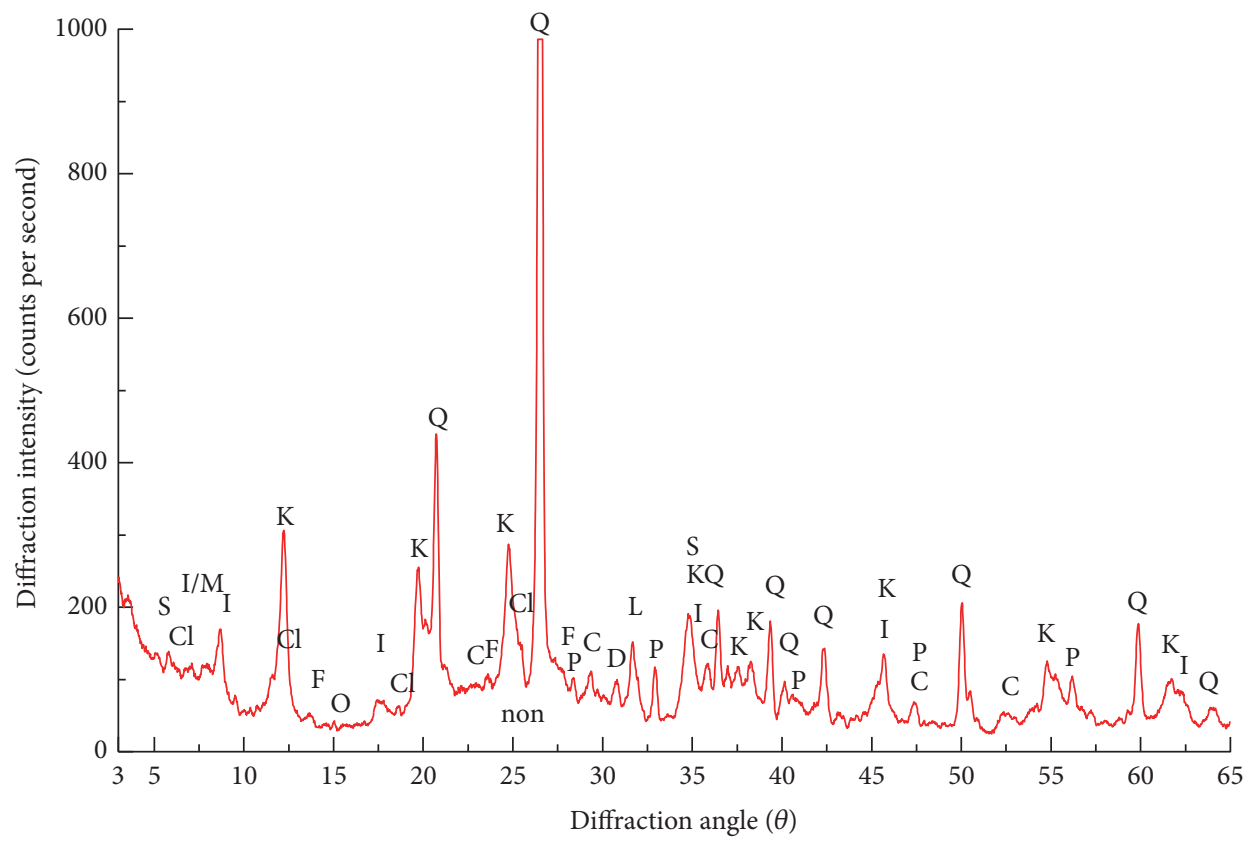

(a) Sample number 1

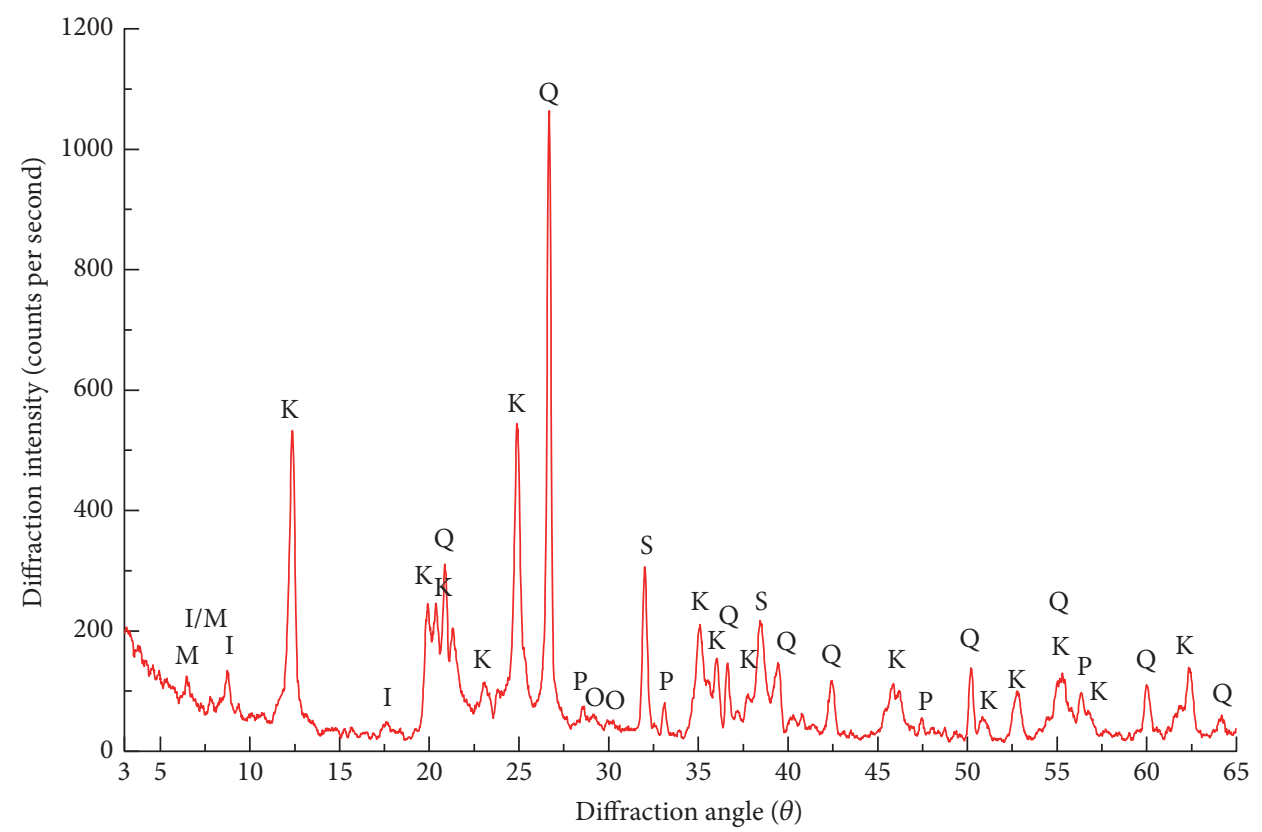

(b) Sample number 2

FIGURE 4: XRD patterns of the fresh coal gangue. (a) Q: quartz (high); K: kaolinite (high); I: illite; I/M: illite-montmorillonite mixed layer; Cl: Chlorite; S: Smectite; D: dolomite (low); P: pyrite; L: siderite; C: calcite (low); F: feldspar; non: amorphous materials; O: others (low). (b) K: kaolinite (high); Q: quartz (high); I: illite (high); I/M: illite-montmorillonite mixed layer; S: siderite; P: pyrite (low); O: others (low).

accounting for $20.7 \%$ and $17.6 \%$ of fresh and weathered coal gangue, respectively. The contents of $\mathrm{SiO}_{2}, \mathrm{Al}_{2} \mathrm{O}_{3}$, and $\mathrm{S}$ in the weathered coal gangue are lower than those in the fresh coal gangue, and the content of $\mathrm{P}$ is slightly increased. The chemical elements also contain a small amount of $\mathrm{Mn}, \mathrm{Cu}$, $\mathrm{Zn}, \mathrm{Ti}, \mathrm{Ba}$, and $\mathrm{Cl}$. Among these elements, the content of $\mathrm{Mn}$ is the highest, that is, $0.054 \%$ and $0.043 \%$ in fresh and weathered gangue, respectively. The contents of each element in the coal gangue are reduced after weathering.
5.3. Screening of the Potential Water Pollution Component in Coal Gangue. The quality assessment criteria for water quality involve pollutant limits, which are a key indicator of whether coal gangue has an impact on the water quality. According to the status quo of groundwater quality in China, the standard of human health, and environmental protection target of groundwater quality and based on the highest water quality requirement of drinking, industrial, and agricultural water, the groundwater quality is 


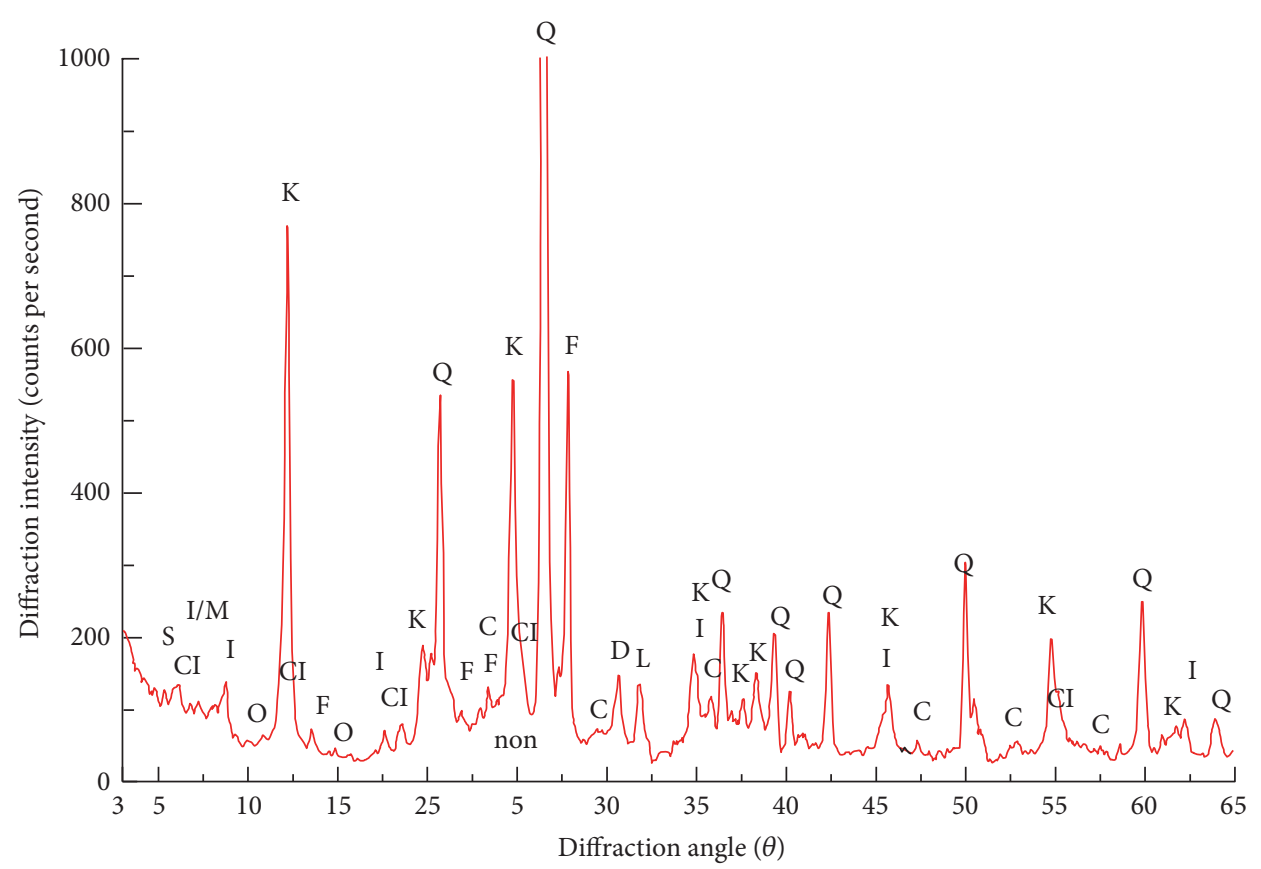

(a) Sample number 1

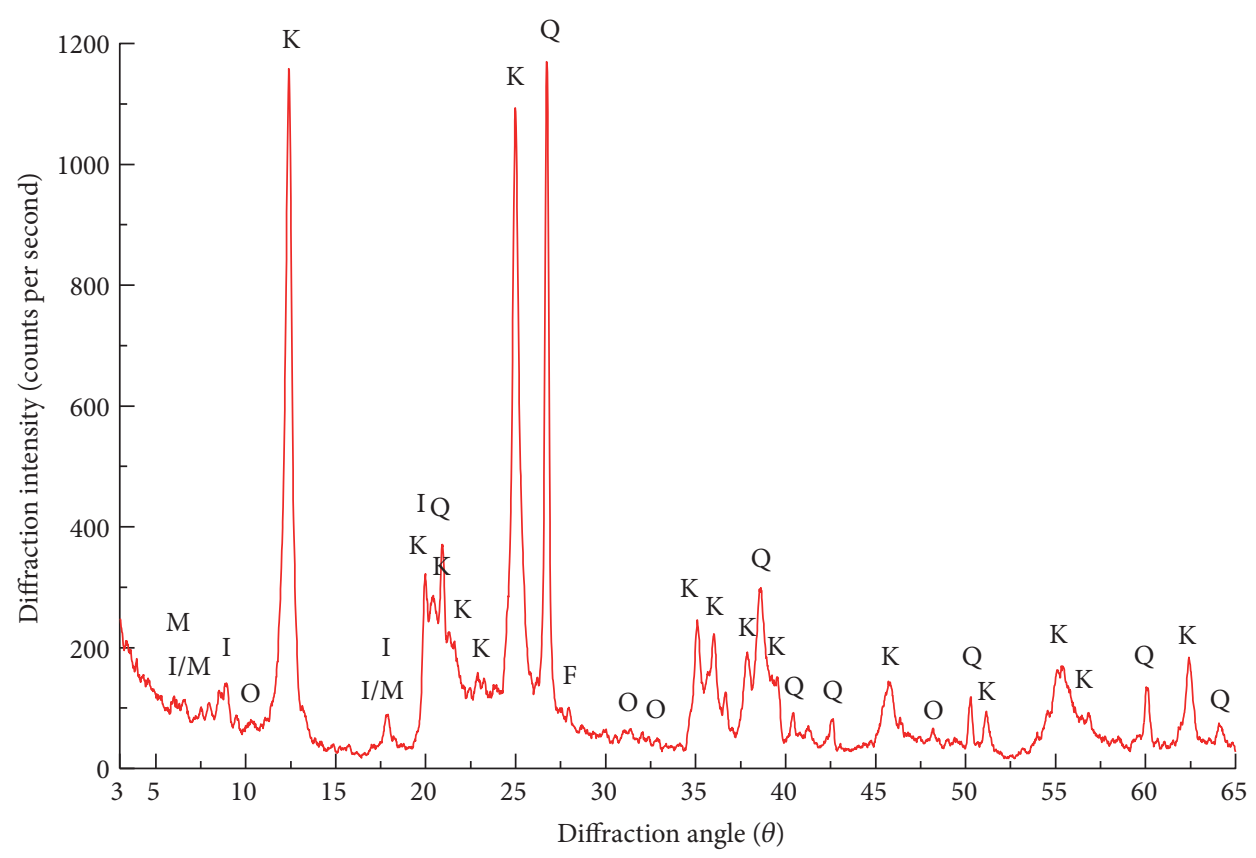

(b) Sample number 2

FIGURE 5: XRD analysis of the weathered coal gangue. (a) Q: quartz (high); K: kaolinite (high); F: feldspar; Cl: Chlorite; I: illite (high); I/M: illite-montmorillonite mixed layer; S: smectite (low); D: dolomite (low); L: siderite (low); C: calcite (low); non: amorphous materials; O: others (low). (b) K: kaolinite (high); Q: quartz (high); I: illite (high); I/M: illite-montmorillonite mixed layer; M: montmorillonite; F: feldspar (low); O: others (low).

divided into five categories. Class I mainly reflects the natural low background content of the chemical composition of groundwater. Class II mainly reflects the natural background content of the chemical composition of groundwater. Class III is based on the human health reference value, which is mainly applicable to the centralized drinking water source as well as to the agricultural and industrial water. Class IV class is based on agricultural and industrial water requirements but can further be used in drinking water after appropriate treatment. Class V is not suitable for drinking; other types of water applications can be selected according to the usage purpose. The supplementary material available online at https://doi.org/10.1155/2017/3128549 shows the classification index of the groundwater quality in China. 
TABle 1: Mineral composition of fresh and weathered coal gangue (\%).

\begin{tabular}{lcccccc}
\hline Sample & Quartz & Kaolinite & Illite & Illite-montmorillonite mixed layer & Smectite & Chlorite \\
\hline Fresh coal gangue & 20 & 33 & 5 & 8 & 2 & 2 \\
Weathered coal gangue & 21 & 42 & 15 & Siderite & 3 & Pyrite \\
\hline & Feldspar & Dolomite & Calcite & 1.3 & 1.6 & 6 \\
\hline Fresh coal gangue & 20 & 0.5 & 0.5 & 1 & 0 \\
Weathered coal gangue & 5 & 1 & 0.2 & 3.7 \\
\hline
\end{tabular}

TABLE 2: Chemical composition of coal gangue (\%).

\begin{tabular}{lcccccccccc}
\hline Sample & $\mathrm{Na}_{2} \mathrm{O}$ & $\mathrm{MgO}$ & $\mathrm{Al}_{2} \mathrm{O}_{3}$ & $\mathrm{SiO}_{2}$ & $\mathrm{~K}_{2} \mathrm{O}$ & $\mathrm{CaO}$ & $\mathrm{Fe}_{2} \mathrm{O}_{3}$ & $\mathrm{P}$ & $\mathrm{S}$ \\
\hline Fresh coal gangue & 0.65 & 1.8 & 20.7 & 59.9 & 2.4 & 2.0 & 6.7 & 0.05 & 1.53 \\
Weathered coal gangue & 0.41 & 1.4 & 17.6 & 53.7 & 2.0 & 1.3 & 5.4 & 0.06 & 0.44 \\
\hline & $\mathrm{F}$ & $\mathrm{Ba}$ & $\mathrm{Mn}$ & $\mathrm{Cu}$ & $\mathrm{Pb}$ & $\mathrm{Zn}$ & $\mathrm{Ti}$ & $\mathrm{Cl}$ & $\mathrm{F}$ \\
\hline Fresh coal gangue & $\leq 0.045$ & 0.10 & 0.054 & 0.0006 & $<0.0002$ & 0.009 & 0.50 & 0.011 & $\leq 0.045$ \\
Weathered coal gangue & $<0.045$ & $\leq 0.002$ & 0.043 & 0.0005 & $<0.0002$ & 0.005 & 0.42 & 0.009 & $<0.045$ \\
\hline
\end{tabular}

TABle 3: Experimental design.

\begin{tabular}{lcc}
\hline Sample & Weathering degrees & $\mathrm{pH}$ \\
\hline Number 1 & Fresh coal gangue & 5 \\
Number 2 & & 7 \\
Number 3 & & 9 \\
\hline Number 4 & Weathered coal gangue & 5 \\
Number 5 & & 7 \\
Number 6 & 9 \\
\hline
\end{tabular}

According to the current evaluation criteria of water environment quality and the test results of coal gangue composition, the main potential pollution components were determined as $\mathrm{Fe}, \mathrm{Mn}, \mathrm{Cu}, \mathrm{Zn}, \mathrm{Pb}, \mathrm{Cd}, \mathrm{As}, \mathrm{Be}, \mathrm{Hg}, \mathrm{Se}, \mathrm{Ca}$, and $\mathrm{Na}$.

\section{Precipitation Mechanism of Heavy Metal Elements in Coal Gangue Backfilling}

The coal gangue filled in the goaf is subject to mine water leaching and soaking or actions of other media. As a result, the heavy metals and inorganic salt components are dissolved in water and can be released from the coal gangue. In this study, the release mechanisms of the heavy metal elements in coal gangue with different weathering degrees were analyzed at different alkaline conditions by using a coal gangue soaking test method under indoor temperature. The concentration of heavy metal ions that precipitated from the coal gangue was used as the detection index, and the distilled water with the initial $\mathrm{pH}$ value of 7 was used as the basic solution.

\subsection{Experimental Design of Static Immersion Leaching of Coal Gangue}

6.1.1. Experimental Design. To study the precipitation and release characteristics of heavy metal elements $\mathrm{Mn}, \mathrm{Cu}, \mathrm{Zn}$,

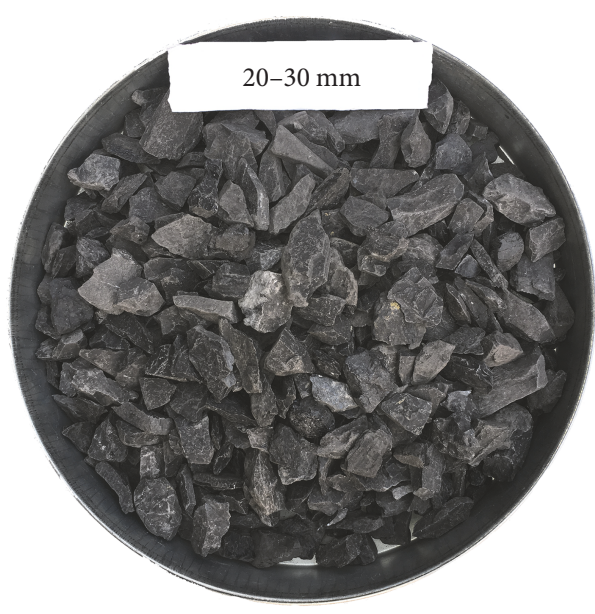

Figure 6: Gangue with particle size $20-30 \mathrm{~mm}$.

$\mathrm{Pb}$, and $\mathrm{Cr}$ in the coal gangue with different weathering degrees under different $\mathrm{pH}$ conditions, an orthogonal experiment was designed (Table 3). To ensure accuracy of the test data, each test was repeated three times.

6.1.2. Experimental Procedures. The particle size of gangue fillings used in solid backfilling coal mining is generally not more than $50 \mathrm{~mm}$. To make the precipitation of the potential pollution components more intuitive, samples of single-particle-size-grade coal gangue were obtained from the Pingdingshan 12 mine for this experiment. The gangue freshly mined out of the Pingdingshan 12 mine was used as the fresh coal gangue, and the gangue from the waste gangue hill was used as the weathered coal gangue. First, the gangue was broken, and the gangue with a diameter of 20-30 mm was selected through a grading screen (see Figure 6), and then, the gangue was inserted into the incubator, dried for $24 \mathrm{~h}$ at $105^{\circ} \mathrm{C}$, and finally placed in a jar and sealed to be used as the test sample. 


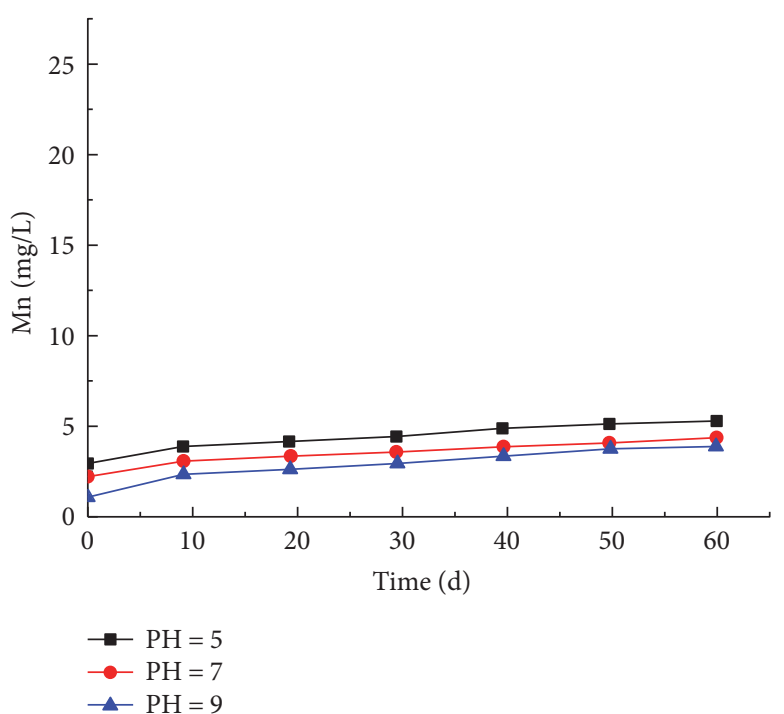

(a) Fresh gangue

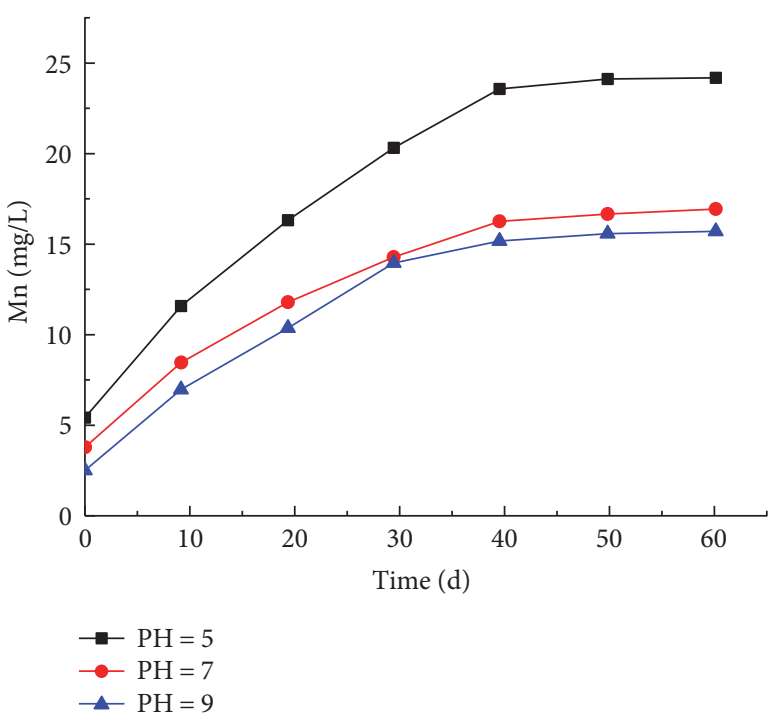

(b) Weathered gangue

Figure 7: Mn element.

A certain amount of coal gangue samples was weighed and placed in a large-capacity plastic bucket. Leaching solutions with $\mathrm{pH}=5,7$, and 9 were added. The solid-liquid volume ratios were maintained at 1:10 and remained unchanged. Aliquots were removed every $10 \mathrm{~d}$ for sampling. Next, the solution was stirred for $1 \mathrm{~h}$ before sampling, and then, the stirring was stopped. After settlement, a clear supernatant, which was the test solution, was obtained. The test solution was put into a bottle, sealed, and labeled. After the solutions were collected, the collected solution was detected using an ICP atomic emission spectrometer. After the detection, the residual waste liquid was collected for centralized processing treatment. Eighteen test solutions were collected for this test.

6.2. Analysis of Experimental Results of the Static Immersion Leaching of Coal Gangue. The precipitation of heavy metal elements in the coal gangue under different $\mathrm{pH}$ conditions shows similar trends. Owing to the limitation of space, this paper only analyzed the Mn element as an example; the results of which are shown in Figure 7.

The following observations are derived from Figure 7.

(1) The precipitation of heavy metal elements under different $\mathrm{pH}$ conditions shows similar trends. The precipitation process is divided into three stages: the presoaking, soaking, and end-of-the-soaking stages. The dissolution release rate in the early stage of immersion is very fast, mainly because of the development of pores, the ability of pores to pass through each other, the large specific surface area of pores; after the solution is immersed in the pores, it can be fully contacted with the gangue and easily flow, resulting in heavy metal elements of coal gangue with a faster dissolution and release rate; then, the dissolution release rate relatively slows in the middle of the soaking process, mainly because coal gangue particles are dissolved or even broken by the interaction between coal gangue and immersion solution, so decreased pores hinder the flow of the solution with the immersion time and the decreased specific surface area between the solution and the pores result in a decreased dissolved release rate of heavy metal elements. And the dissolution release rate tends to be stable toward the end of the soaking. The concentration of heavy metal elements in the soaking solution gradually increases with the immersion time, while the precipitation rate gradually decreases.

(2) Under the same conditions, the heavy metal elements that precipitated from the weathered coal gangue were obviously higher than those that precipitated from the fresh coal gangue. When the $\mathrm{pH}$ value is 5 , the concentration of $\mathrm{Mn}$ ion in the soaking solution was $5.686 \mathrm{mg} / \mathrm{L}$ for the fresh gangue after $60 \mathrm{~d}$ of leaching. In contrast, the concentration of $\mathrm{Mn}$ ion in the soaking solution is $25.138 \mathrm{mg} / \mathrm{L}$ for the weathered gangue after the same leaching period; this is 4.4 times that of the fresh coal gangue. This is mainly because of the relatively loose structure and significant development of coarse holes and fractures of coal gangue after weathering; this significantly increased the contact area of the gangue and the solution in the immersion process and promotes the precipitation of heavy metal ions in coal gangue.

(3) The degree of pollution risk to the groundwater environment when using the weathered coal gangue as a filling for the goaf area is obviously higher than that when using the fresh gangue. Thus, the gangue, which is as fresh as possible, should be selected during backfilling to reduce the impact on groundwater environment. 


\section{Conclusions}

(1) The compactness and integrity of coal gangue change remarkably after weathering. The structure of the fresh coal gangue is relatively dense, and large pores and fractures are not developed. The structure of the weathered gangue is relatively loose, with obvious development of large pores and fractures.

(2) The mineral compositions of fresh and weathered coal gangue are not significantly different. In addition, the main components are quartz and kaolinite, along with some illite, illite-montmorillonite mixed layer, and a small amount of chlorite, siderite, pyrite, and so forth. The content of kaolinite and illite after coal gangue weathering was significantly increased, while the content of feldspar significantly decreased.

(3) In the composition of coal gangue, $\mathrm{SiO}_{2}$ is the main component, followed by $\mathrm{Al}_{2} \mathrm{O}_{3}$. The content of $\mathrm{SiO}_{2}, \mathrm{Al}_{2} \mathrm{O}_{3}$, and $\mathrm{S}$ in the weathered coal gangue was lower than that in the fresh coal gangue, while the content of $\mathrm{P}$ was slightly higher. Chemical elements contain a small amount of $\mathrm{Mn}, \mathrm{Cu}, \mathrm{Zn}, \mathrm{Ti}$, $\mathrm{Ba}, \mathrm{Cl}$, and other elements, among which the content of $\mathrm{Mn}$ is the highest. Moreover, the contents of each element in coal gangue reduced after weathering.

(4) Under the same conditions, the heavy metal elements precipitated from the weathered coal gangue are obviously higher than those precipitated from the fresh coal gangue. This is mainly because of the relatively loose structure and significant development of coarse holes and fractures of coal gangue after weathering, which significantly increases the contact area of gangue and the solution in the immersion process and promotes the precipitation of heavy metal ions in the coal gangue.

\section{Conflicts of Interest}

The authors declare that they have no conflicts of interest.

\section{Acknowledgments}

The financial support for this work was provided by the Fundamental Research Funds for the Central Universities (2015XKMS001) and the National Natural Science Foundation of China (no. 51774269).

\section{References}

[1] J. Zhang, Study on Strata Movement Controlling by Raw Waste Backfilling with Fully-Mechanized Coal Winning Technology and Its Engineering Applications, China University of Mining and Technology, Xuzhou, 2008.

[2] J. Zhang, X. Miao, and G. Guo, "Development status of backfilling technology using raw waste in coal mining," Journal of Mining \& Safety Engineering, vol. 26, no. 4, pp. 395-401, 2009.
[3] Y. Huang, Ground Control Theory and Application of Solid Dense Backfill in Coal Mines, China University of Mining and Technology, Xuzhou, 2012.

[4] H. Jiang, "Harmfulness of coal gangue to environment and its comprehensive treatment and utilization," Coal Processing and Comprehensive Utilization, vol. 03, pp. 43-46, 2003.

[5] J. Ye, G. Shen, and L. Lu, "Hazards and comprehensive utilization of coal gangue," China Resources Comprehensive Utilization, vol. 05, pp. 32-34, 2010.

[6] X.-G. Wu, Mechanical Properties of Solid Filling Materials Research and Application, China University of Mining and Technology, Xuzhou, 2014.

[7] R. Li and L. Wu, "Research on characteristic indexes of weathering intensity of rocks," Chinese Journal of Rock Mechanics and Engineering, vol. 22, pp. 3830-3833, 2004.

[8] Y. J. Shang, S. J. Wang, Z. Q. Yue, R. L. Hu, and X. B. Tu, "Variation features of pore radius and particle diameter distributions and mineral content of completely decomposed granite and correlation of parameters," Rock and Soil Mechanics, vol. 25, no. 10, pp. 1545-1550, 2004.

[9] X. Li, Study on the Influence of Coal Gangue on Environment and Reuse, Chang'an University, Xi'an, China, 2006.

[10] F. Li, J. Zheng, and Y. Deng, "Leaching experiments with gangue of different diameters simulating the environmental influence after filling-in coal mine," Journal of Henan Polytechnic University, vol. 25, no. 2, pp. 101-103, 2006.

[11] X. Fan, L. Chen, S. Wang et al., "Analysis of geting bituminous coal by electrospray ionization and direct analysis in real time mass spectrometry," Analytical Letters, vol. 47, no. 12, pp. 2012-2022, 2014.

[12] X. Fan, C. Wang, C. You et al., "Characterization of a Chinese lignite and the corresponding derivatives using direct analysis in real time quadrupole time-of-flight mass spectrometry," RSC Advances, vol. 6, no. 107, pp. 105780-105785, 2016. 

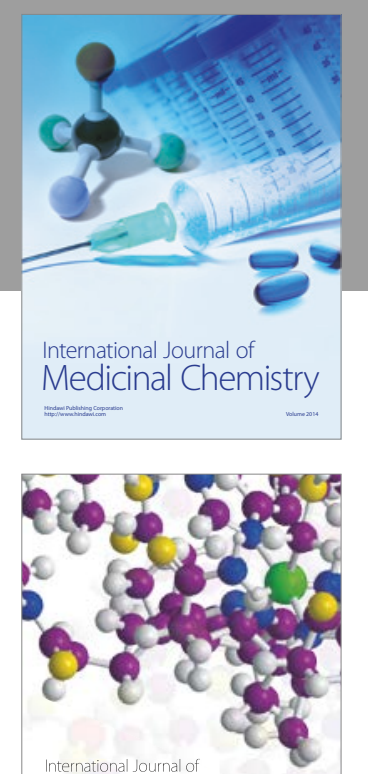

Carbohydrate Chemistry

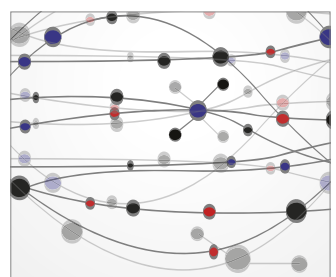

The Scientific World Journal
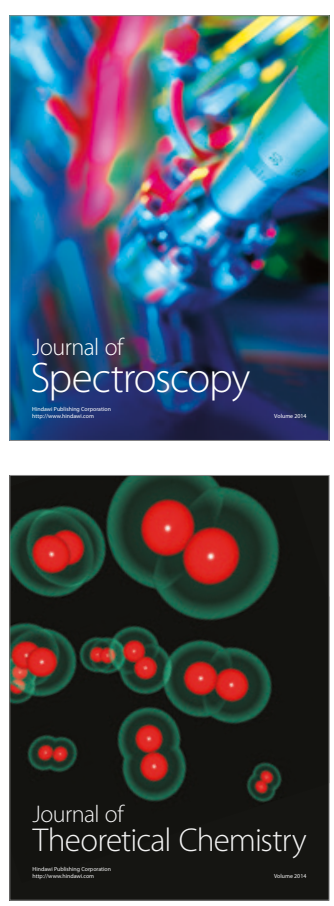
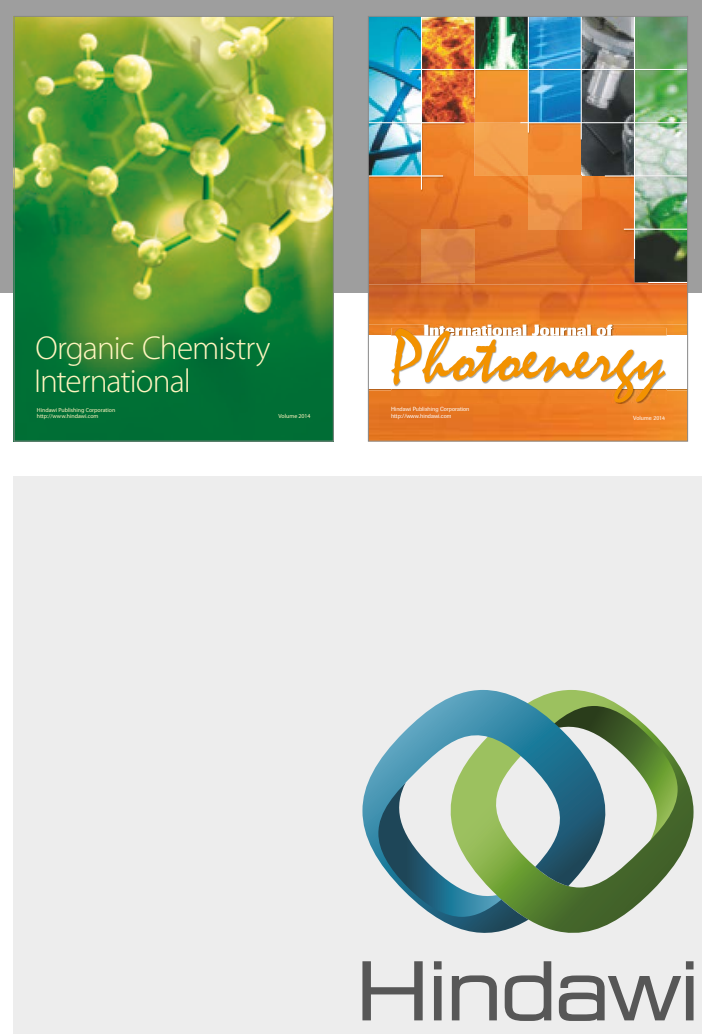

Submit your manuscripts at

https://www.hindawi.com

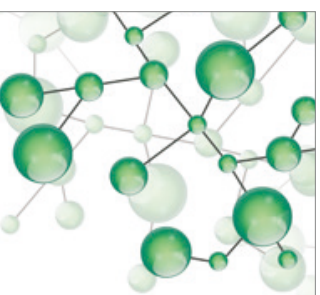

International Journal of

Inorganic Chemistry

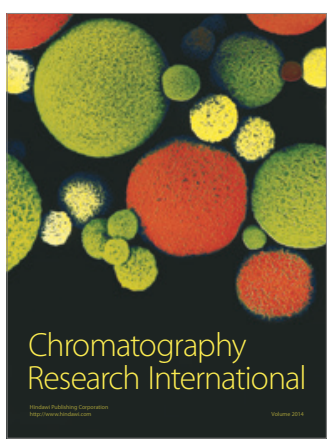

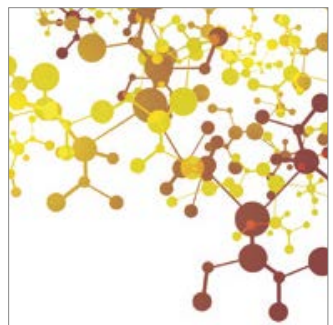

Applied Chemistry
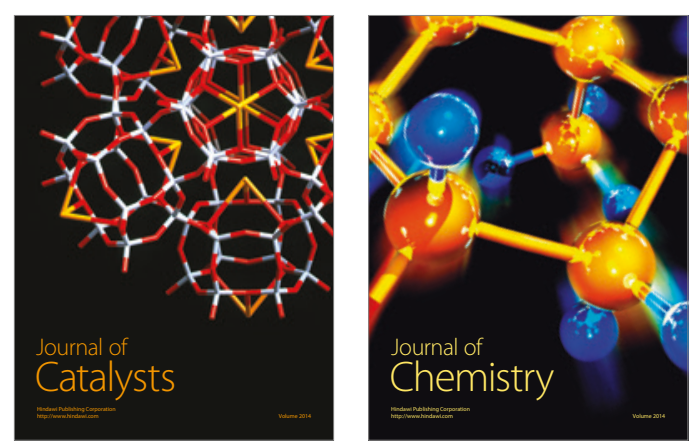
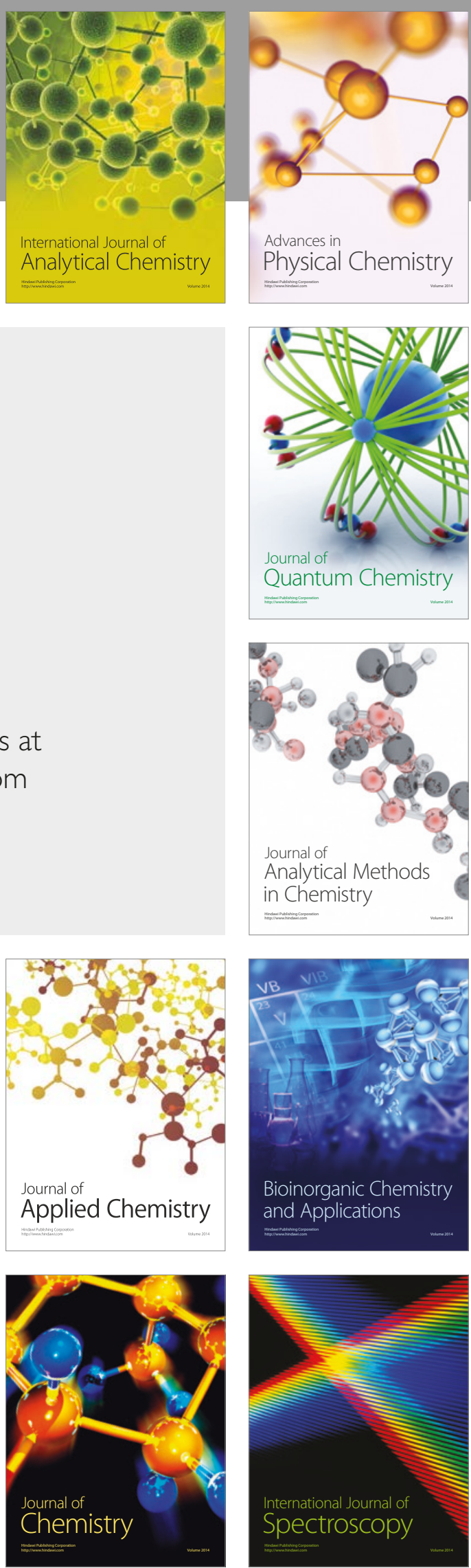